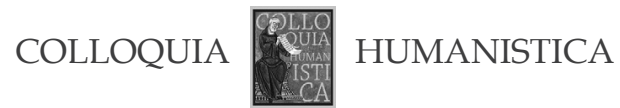

Maciej Falski
Institute of Western and Southern Slavic Studies
University of Warsaw
Warsaw
mf.falski@gmail.com
Tomasz Rawski
Institute of Sociology
University of Warsaw
Warsaw
rawski00@gmail.com

\title{
Against Homogeneity. Transcultural and Trans-Lingual Strategies in Cultural Production
}

7 he key idea of the present volume of Colloquia Humanistica is the struggle against homogeneity. All the papers deal with the problem of homogenous narratives and homogenous practices, which most often falsify the complex reality of the human world. No matter if we look for examples in literature, cinema, or if we take a closer look at cultural institutions; our authors question the apparent uniformity which seems to lie behind the familiar categories we use to describe our everyday experience. The languages we speak, books we read, exhibitions we visit - they are supposed to use clearly defined categories with sharp boundaries and unified content. This unwritten agreement makes our life easier and helps us move through the labyrinth of social relations and cultural patterns. But what if we suddenly find out that one of those well-known categories does not suit the reality? Or,

This is an Open Access article distributed under the terms of the Creative Commons Attribution 3.0 PL License (creativecommons.org/licenses/by/3.0/pl/), which permits redistribution, commercial and non-commercial, provided that the article is properly cited. (C) The Author(s), 2018 Publisher: Institute of Slavic Studies, Polish Academy of Sciences

Editor-in-chief: Jolanta Sujecka

Conception and academic editing of this issue: Maciej Falski, Tomasz Rawski, Jolanta Sujecka with the collaboration of Ewa Niedziałek 
what if we feel uneasy with groups in which we are supposed to participate but our intuition tells us we do not fit in?

We do not enter into a psychological debate on personality as a dimension of the self. The aim is to open a discussion about the ways we participate in social life, forcing us to accept every categorization as it is. Indeed, the authors represented in this volume try to break through the rigidity of homogenic cultural forms. They all exploit possible modes of escaping such cultural constraints. That is why we decided to stress this pursuit of liberation in the volume's title. The old dream of the avantgarde, to find a completely new language for completely new forms of social life, lost its attractiveness years ago. The intellectual freshness of the poststructuralist negation of any subjectivity has vanished. Our approach is thus not a negation but an investigation into how we can transcend existing limitations. That is why we propose to talk about phenomena which are "beyond" language and culture, which are "trans", i.e. transcultural or trans-lingual. The present volume offers a few cases chosen within the vast space of cultural production which show us how the notion of strategy may be useful for our purpose. Again, writing about strategies indicates clearly that the issue of that quest for "the beyond" can be found between already worn-out behaviours.

Readers can find probably the best illustration of the aforementioned approach in the paper by Ewa Niedziałek. Her attention is focused on Nadine Gordimer's novel Burger's Daughter. She invites us to read it as an example of a strategy aimed at satisfying the desire of the transcultural. Gordimer strove to express a space "beyond culture", beyond cultural and societal attachments. How does one transcend any simplifying categories? The author states that the main figure of coercion is language. For that reason Gordimer would try to weaken its rigidity and omnipresence. It is true that we cannot exist beyond language, but - as Niedziałek puts it clearly - we could try to overcome it. The novelist reaches for different mechanisms, like strengthening the visuality, introducing plural voices, maintaining a distance from the storyline. That place "beyond culture" does not exist, it's even hard to imagine, but the text shows us how the notion of strategy can be functional in this pursuit of not being trapped.

Keiko Miller turns readers' attention to a different part of the world, but the problem, in its very basis, remains similar. A Japanese Buddhist monk, Kukai, is described by Miller not only as the inventor of the hiragana, the Japanese syllabic alphabet. The author argues that his work can be interpreted as a quest for transcendence, where the invention of the hiragana might be seen as a part of that bigger project. Kukai would achieve the transmission of esoteric Buddhism, combining Japanese linguistic features with Chinese 
linguistic and philosophical traditions. For him, the crucial question is: which instruments could be helpful on the way to transcendence, how does one go "beyond still existing culture" and its linguistic habits?

The topic of a non-existing place, or a "non-place", returns in the paper by Miranda Levanat-Peričić. She draws attention to phenomena slightly different from the two other cases. Analysing post-Yugoslav novels, she deals with the people who didn't look for such non-places but were forced to go through them, and that very experience becomes their overwhelming identity factor. The dissolution of the Yugoslav state resulted in the creation of different political and cultural units, each with its new narratives; another consequence was exile, the destiny of those who tried not to accept new identities. The author shows that even those people who didn't choose exile have to assume the same disintegration of space and time. There are some rhetoric instruments and topics repetitively used by cited novelists, helping them to express what is beyond ordinary societal experience: the absence of home, or home represented as a mental and not real phenomenon, confrontation with "the other", different by culture, and travel, moving, a metaphor for being unrooted. We could risk the observation that for some authors the transcultural "non-place" represents a kind of contemporary locus amoenus, where individuals are not forced to endure the oppression of unifying narratives and practices. However, in Levanat-Peričić's paper that Arcadian tone vanishes, leaving space for the difficult experience of non-belonging.

Two papers that speak against homogeneity in such a way that they address the issue of cultural heterogeneity in literary works are those by Rezoničnik and Mitevski. Lidija Rezoničnik, in her literary analysis of Rebellion in der Gottschee by Karl Rom, a German historical novel from the late 1930s concerning the great 16th-century peasant revolt in Slovenia (Carniola), shows how political mechanisms of national homogenization "work" in literature. More precisely, Rezoničnik deconstructs the romanticnationalist presentism of the novel's author by analysing the juxtaposed literary images of two language communities taking part in the peasant rebellion: Slavs (Slovenes) and Germans (Gottschee Germans). She shows how the author's political goal, i.e. to promote German national feelings among Gottscheers, shaped his literary image of the Carniolan locality as a space where two separate, homogeneous cultures live side by side, being averse to any influences from the outside. As Rezoničnik argues, this writing strategy completely overshadowed the real specificity of 16thcentury Carniola, which constituted a single, internally diverse cultural whole, created and maintained in centuries-long mutual interactions of two neighbouring communities. 
On the other hand, Vitomir Mitevski in his article does not look for a clash between homogeneity and heterogeneity, but points to the crucial importance of multidirectional cultural influences between different levels: macro (Indo-European), mezzo (Byzantine) and micro (Macedonian). In his comparative literary analysis of the motif of the borderland warrior in traditional Byzantine and Macedonian epic poetry, juxtaposed with Homeric heroes, Mitevski reveals how a macro-cultural Indo-European pattern is reproduced in a regional or local context in a very specific way. Furthermore, by uncovering several common points between the Byzantine akritic hero and the Macedonian krajishnik, Mitevski convincingly demonstrates a close relationship between these two cultures without prejudging the existence of power relations between them.

Two other papers that are worth reading together are those by Kamusella and Vuković, since they both show the ways homogeneity, this time understood as a hegemonic principle of political action employed by different polities, can be counteracted, circumvented and possibly dismantled by various institutional actors. The article by Tomasz Kamusella addresses the issue of Russian language policy in the post-Soviet area. Starting from the observation that contemporary Russian is the world's only 'big' language of monocentric character, i.e. that despite being employed as an official language in numerous post-Soviet states (and Israel), its standard is controlled solely by Russia, Kamusella considers the potential of its pluricentrization. The author shows why and how the monocentric character of the Russian language fosters Moscow's current neo-imperial policy, which has turned the language issue into the foundation of its expansive ideology of the 'Russian World' ('Russkii Mir'). Then, he outlines a path to the linguistic redefinition of Russian as a pluricentric language, which would, as he argues, result in its de-ethnicization and would benefit political stability in the region, from the perspective of both Russia and neighbouring countries.

Tijana Vuković, in her article on cultural institutions in Serbia in transition, argues for the key importance of the Yugoslav narrative for (re) establishing their structural continuity and coherence. On the example of selected activities of the Museum of Contemporary Art in Belgrade after 2000, aimed at defining the role of the Museum as the leader in bringing out Yugoslav heritage and Serbian contemporary art, Vuković reveals the longevity of the concept of the Yugoslav Artistic Space at the narrative level. She points out that attempts at reconstructing the Yugoslav Artistic Space, a common ground for heterogeneous cultural and artistic activity deeply rooted in the region's history, could be a step towards breaking the impasse of Serbian cultural institutions into which they were pushed by the isolationist, homogenizing nationalist state policy of the 1990s. 
Let us return once again to the notion of strategy. As mentioned earlier, it could help us to understand that the quest for "the beyond" might be described not in terms of a static definition but as a dynamic process. Transcending what is given does not imminently lead to the creation of a new being. And the same can be true for still existing but unobvious phenomena. When they elude definition, transcending clear boundaries, a strategy of approaching them from different points of view could be possible. This is the case considered by Amir Kapetanović. His analysis shows three stages of creating what is seemingly the same story, where differences appear when different media are used. Vatroslav Mimica's film Kaya was an adaptation of Kruno Quien's novella. But there was an intermediary step, a screenplay, in which slight changes can be noticed. The overview of structural and narrative features of the screenplay reveals how some crucial effects of the film were invented. One of them is the representation of "Mediterreneanness", a specific ambiance which plays an extremely important role in the film. It is impossible to describe it with words: while it lies "beyond language", other instruments should have been used, above all the local dialect in its audial form.

If the conclusion was that the world is complex but our language and social habits irritatingly simplify it, our contribution would not be worthy of notice. Meanwhile, the strength of Colloquia Humanistica has always been the confrontation of different academic positions within the field of social and human sciences. If we combine literary analysis with cinema, linguistics or historical contextualization of folklore, we receive a broader view of the whole issue. The hegemony of homogeneity was questioned in various cases, which served as a laboratory. It seems that all the papers show the leading role of strategy as a dynamic notion, helping us to imagine possible ways of challenging homogeneity. This last term may have different avatars: a " $p$ or $\mathrm{q}$, not $\mathrm{p}$ then q" model of logic and linguistics, a language policy imposing a unique linguistic standard, or a narrowly focused narrative of national art history. Our authors show that negation of the old and imposition of another model is not a solution: it would not be possible, or it would lead to another simplification senza fine. Here, in the present volume, readers can find some examples of strategies and find out how to maintain vigilance and avoid the trap of categories. For the contemporary scholar, metaphors such as "the beyond" or "the trans" keep their freshness and seem more accurately to describe the problems of being-in-culture. It would be our, the readers', task to evaluate if this is just another academic fad or an interesting proposition that might influence our cultural imaginary. 


\section{Note}

Maciej Falski, Institute of Western and Southern Slavic Studies, University of Warsaw, Warsaw

mf.falski@gmail.com

Tomasz Rawski, Institute of Sociology, University of Warsaw, Warsaw rawski00@gmail.com

The preparation of the article was self-funded by the authors.

No competing interests have been declared.

The authors participated in the article in equal parts (50/50\%).

T. Rawski i M. Falski conceived of the presented idea. T. Rawski developed the theoretical background, M. Falski verified the coherence of presented ideas. All authors discussed the results and contributed to the final manuscript. 